\title{
Grouping and genetic diversity of different watermelon ecotypes based on agro-morphological traits and ISSR marker
}

\author{
Zeynab Norelahi Soghani', Mehdi Rahimi ${ }^{2}$, Maryam Abdoli Nasab² \& Mahmood Maleki²
}

\author{
'Graduate University of Advanced Technology Faculty of Sciences and Modern Technologies, \\ Department of Biotechnology, Kerman, Iran \\ ${ }^{2}$ Graduate University of Advanced Technology Institute of Science and High Technology and Environmental Sciences, \\ Department of Biotechnology, Kerman, Iran. mehdi83ra@yahoo.com
}

Received on 09.XI.2016

Accepted on 22.V.2018

DOI 10.21826/2446-8231201873107

\begin{abstract}
The genetic diversity of 38 ecotypes of watermelon was evaluated using genetic markers and morphological traits. Analysis of variance showed a significant difference for the studied traits. Cluster analysis using UPGMA method based on morphological traits was classified studied ecotypes into four groups. Using 11 primers were obtained 89 polymorphic bands that cluster analysis of molecular data was placed 38 ecotypes into four groups. The genetic diversity structure of the watermelon accessions on the basis of ISSR data evidenced a common pattern of molecular markers. The similarity of ecotypes grouping with molecular markers and morphological traits was low and the correlation coefficient of the twomatrices was low $(\mathrm{r}=0.03)$, revealing quite a non-significant correlation between them and the efficiency of them to assays in estimating genetic diversity in watermelon is different. Overall, this study demonstrated high genetic diversity among cultivated watermelon which may be attributed to their high genetic background and environmental effects.
\end{abstract}

Keywords: genetic diversity, ISSR, marker

RESUMO - Agrupamento e diversidade genética de diferentes ecótipos de melancia com base em características agro-morfológicas e ISSR. A diversidade genética de 38 ecótipos de melancia foi avaliada usando marcadores genéticos e características morfológicas. A análise de variância mostrou diferença significativa para os caracteres estudados. A análise de agrupamento usando o método UPGMA baseado em características morfológicas foi classificada os ecótipos em quatro grupos. Utilizando 11 primers foram obtidas 89 bandas polimórficas que agruparam a análise de dados moleculares em 38 ecótipos em quatro grupos. A estrutura de diversidade genética dos acessos de melancia com base nos dados do ISSR evidenciou um padrão comum de marcadores moleculares. A semelhança do agrupamento de ecótipos com marcadores moleculares e características morfológicas foi baixa e o coeficiente de correlação das duas matrizes foi baixo $(\mathrm{r}=0,03)$, revelando uma correlação bastante significativa entre eles e a eficiência dos mesmos em estimar a diversidade genética em melancia é diferente. No geral, este estudo demonstrou alta diversidade genética entre a melancia cultivada, o que pode ser atribuído ao seu elevado background genético e efeitos ambientais.

Palavras-chave: diversidade genética, ISSR, marcador

\section{INTRODUCTION}

Watermelon is native to Africa and it is a fruit crop that belongs to the Cucurbitaceae family. It spread in many parts of the world and was grown in temperature and tropical regions (Dane \& Liu 2007). According to FAO statistics in 2014 (FAO World) China have taken in first place with $67.61 \%$ production ( 75054330 ton) and Turkey (3885617 ton), Iran (3568134 ton) and Brazil (2171448 ton) are in the next place. Iran dedicated to about 132786 hectares in terms of cultivated area, with an average production of $23008 \mathrm{~kg}$ per hectare (Faostat 2014). The study of genetic diversity is important not only to organize protection of plant material, but is also important for utilization of heterosis and hybrid seed production with high heterosis terms of performance, environmentally and tolerance to biotic and abiotic stresses (Muhammed 2012).

Assessing genetic diversity of germplasm and the relationship between them have been considered from the distant past for effective utilization of genetic resources.
These estimates are usually based on the evaluation of agronomic traits and or the use of molecular markers. Genetic resources are a fraction of biodiversity that is expected to have a current or potential use to improve landraces, varieties, advanced lines and native species (Muhammed 2012) To carry on a watermelon breeding program it is really necessary to study the genetic diversity contained in crop germplasm. Morphological descriptors have been used by breeders to characterize, register and release new varieties (Hamrick \& Godt 1996). However, the limitations of this type of descriptor have created the need to find alternatives, one of which is the DNA descriptor based on the genotype of the individuals that have been highlighted, especially because of their potential to distinguish morphologically similar and genetically related genotypes. Molecular markers are alternatives to characterize germplasm and protect new cultivars without environmental interference (Nybom 2004). DNA markers have the advantage of being independent of environmental effects and providing 
direct information on the genome of each individual (Lefebvre et al. 2001).

An important step in cultivar development is studying the genetic variability found in genetic resources. The use of genetic resources to create new varieties is important for obtaining higher yields and for the technological transformations required for modernization of agribusiness. It is a dynamic process, but requires continuous enrichment and characterization of the materials maintained in germplasm collections (Zang \& Jiang 2001). Molecular information can complement ecological, morphological, and agronomic information on genetic resources; increase the efficiency of collection processes; direct enrichment of the genetic base; help form and validate nuclear and study collections; reveal genetic diversity and purity; identify duplicate and redundant accessions; facilitate botanical and phylogenetic classification studies; subsidize parent selection, and help plan crossing and selection of genotypes with desired characteristics in breeding programs (Mondini et al. 2009).

Capeloto et al. (2004) studied genetic divergence within and between 18 watermelon accessions collected in Maranhão State with 59 RAPD (random amplified polymorphic DNA) primers and concluded, based on clustering analysis, that there was considerable divergence among and between accessions. RAPD markers have the disadvantages of being dominant and difficult to reproduce (Mondini et al. 2009). In contrast, microsatellite markers, also called SSR (simple sequence repeats), have been the best markers for fingerprinting studies because of their polymorphic character, co-dominance, reliability, and reproducibility (Mondini et al. 2009). In spite of these benefits, SSR markers have not been used to analyze genetic variation in the BGCIA accessions. Mujaju et al. (2010) revealed greater within-accession variability in wild Zimbabwean watermelon, based on molecular analysis of variance (AMOVA) and RAPD and SSR data clustering. Studies Jarret et al. (1996), Guerra-Sanz (2002) and Joobeur et al. (2006) revealed genetic variability in watermelon accessions from the formation of clusters with SSR molecular data.

JuFen et al. (2009) reported that three of 73 assessed SSR markers distinguished two watermelon hybrids from their parental lines, but 200 RAPD (Random Amplification of Polymorphic DNA) and 30 ISSR (Inter Simple Sequence Repeat) primers could not differentiate them. The authors further identified Two SSR markers that distinguished the two hybrids assessed, reinforcing the potential of this type of marker for studies on watermelon cultivar protection and commercial dispute arbitration. Levi et al. (2009) applied 40 genetic SSR markers to watermelon accessions and cultivars and found greater diversity among the accessions than the cultivars. Lee et al. (2007) reported that applying 15 SSR was sufficient to differentiate 26 Korean watermelon cultivars, separating them into two groups, but no morphological and physiological associations were observed among the groups formed. In Brazil, the application of markers consists of among and within genetic divergence studies on accessions in germplasm banks, for example, conducted with RAPD markers by Capeloto et al. (2004) and Silva et al. (2006). Although microsatellite markers are available for watermelon, a minimum number of this type of marker has not yet been proposed to help in cultivar protection and commercial dispute resolution. The objectives of the present study were to establish the allele patterns and estimate the genetic distances for 38 watermelon ecotypes from different regions of the Iran based on ISSR marker and agro-morphological traits, generating a reference and support database for cultivar protection and possible commercial dispute arbitration and to guide watermelon breeding programs and genetic resources.

\section{MATERIAL AND METHODS}

\section{Plant material}

In this study, a total number of 38 watermelon ecotypes, which was prepared from Gene Bank of Iran, were chosen for this study on the basis of their yield potential and agronomical traits. Ecotype name, their parentage and releasing centers are given in (Table 1). The experiment was carried out in randomized block design with two replications at research farm of Graduate University of Advanced Technology, Kerman, Iran during 2015 season. Data was collected on morphological characters of watermelon which include leaf, flower, fruit and seed characteristics as: Plant height $(\mathrm{cm})$, Number of nodes (number), Internode length $(\mathrm{cm})$, Plant branches (number), Leaf length $(\mathrm{cm})$, Number of male flowers (number), Days to maturity (day), Fruit length $(\mathrm{cm})$, Fruit width $(\mathrm{cm})$, Fruit length/width ratio, Fruit weight $(\mathrm{kg})$, Flesh weight $(\mathrm{kg})$, Skin thickness $(\mathrm{mm})$, Seed length $(\mathrm{mm})$, Seed width $(\mathrm{mm})$, Seed thickness (mm), pH range, 100-seed weight (gr).

\section{DNA extraction and amplification}

Fresh leaves were used for DNA extraction according to the modified protocol of CTAB protocol described by Murray \& Thompson (1980). Total genomic DNA was extracted separately from 30 to $50 \mathrm{mg}$ of watermelon from each sample and the quality of the extracted DNA was checked by electrophoresis through a $1 \%$ agarose gel. Eleven ISSR primers were used for analyzing genetic diversity in this study. The polymerase chain reaction (PCR) was carried out in a total volume of $10 \mu \mathrm{l}$ per reaction containing $2 \mu \mathrm{l}$ of template DNA $(5 \mathrm{ng} / \mu \mathrm{l}), 1 \mu \mathrm{l} 10 \times \mathrm{PCR}$ buffer, $0.6 \mu \mathrm{l}$ of forward and reverse primers $(5 \mu \mathrm{M}$ stock concentration), $0.6 \mu \mathrm{dNTPs},(2 \mathrm{mM}), 0.48 \mu \mathrm{l}$ of $\mathrm{MgCl} 2$ $(50 \mathrm{mM}) 0.14 \mu \mathrm{l} \mathrm{Taq}$ polymerase $(5 \mathrm{U} / \mu \mathrm{l})$ and and $4.58 \mu \mathrm{L}$ of sterile nano-pure $\mathrm{H} 2 \mathrm{O}$. The PCR amplification reaction was performed in a thermal cycler (Applied Biosystems, Germany) at an initial denaturation temperature of $94^{\circ} \mathrm{C}$ for $5 \mathrm{~min}$, then $35 \mathrm{cycles}$ of $94^{\circ} \mathrm{C}$ for $30 \mathrm{~s}, 55^{\circ} \mathrm{C}$ for $30 \mathrm{~s}$ (primer annealing occurred with most of the primers while some were adjusted), $72^{\circ} \mathrm{C}$ for $2 \mathrm{~min}$ and final extension at $72^{\circ} \mathrm{C}$ for $5 \mathrm{~min}$ and then stored at $4^{\circ} \mathrm{C}$. The PCR products were separated by electrophoresis in $3 \%$ agarose in 0.5 $\mathrm{x}$ tris-borate EDTA (TBE) buffer. The determined PCR bands were detected by safe stain. 
Table 1. Geographical origins and code number of watermelon.

\begin{tabular}{|c|c|c|c|c|c|}
\hline Code & Collection region & Code & Collection region & Code & Collection region \\
\hline G1 & Rabor & G14 & Wimsan swet & G27 & Deh-e Ali-Ravar \\
\hline G2 & Gerd & G15 & Ravar & G28 & Line 16 \\
\hline G3 & Chatrud & G16 & japany & G29 & Sefid \\
\hline G4 & Arzuiyeh & G17 & Rafsanjan & G30 & Torbat-e Heydarieh \\
\hline G5 & Baft & G18 & Hejrak & G31 & Nishapur-local \\
\hline G6 & Aliabad-Zarand & G19 & Sabzevar & G32 & Yazd-Black \\
\hline G7 & SarkarAghaei & G20 & Binam & G33 & Yazd \\
\hline G8 & Soghan & G21 & Line 12 & G34 & Bushire \\
\hline G9 & Line 11 & $\mathrm{G} 22$ & Line 13 & G35 & Razavi Khorasan \\
\hline G10 & Sefid1 & $\mathrm{G} 23$ & Line 14 & G36 & Sistan and Baluchestan \\
\hline G11 & Sefid2 & G24 & Line 15 & G37 & Isfahan \\
\hline G12 & Dasht-e Khak & G25 & Sefid-Zarand & G38 & Qazvin \\
\hline G13 & Zarand-Black & G26 & Sefid-Khareji & & \\
\hline
\end{tabular}

\section{Phenotypic and genotypic analyses}

The data for 19 quantitative characters were analyzed to determine means, standard deviations, and minimum and maximum values of each traits using SAS Ver. 9.3 (SASInstitute 2011). For the quantitative characters the statistical analyses were performed using the $\mathrm{F}$ test and statistical significance was set at $5 \%(p<0.05)$ and the SAS software was used for all tests (SAS-Institute 2011). The software PAST (Hammer et al. 2001) was used for the cluster and principal component analyses. Qualitative and quantitative traits data were analyzed separately. The qualitative traits were transformed into binary data considering the presence or absence $(1 / 0)$ of each character state and distinct bands to form a binary matrix. Number of alleles per locus, Nei's gene diversity $(\mathrm{h})$, polymorphism information content (PIC), genetic distance (GD) and shannon's information index (I) were calculated using Power Marker ver. 3.25 (Liu $\&$ Muse 2005). Cluster analysis was performed to generate a dendrogram using the un-weighted pair group method with arithmetic averages (UPGMA) with DarWin Ver. 6 software (Perrier \& Jacquemoud-Collet 2006). Finally, the Mantel`s test (Diniz-Filho et al. 2013, Mantel 1967) was performed via XLSTAT software.

\section{RESULTS AND DISCUSSION}

The results of Analysis of variance based on a randomized complete block design (data not showed) showed a significant difference between the studied traits at the $1 \%$ significant level which is a reason of the existence of a high diversity among different populations. Minimum, maximum and range of the studied traits are indicated in Table 2. According to Table 2 number of leaf, number of male flowers, plant branches, flesh weight and seed length had the highest coefficient of phenotypic variation. Therefore, it can be used these traits for breeding and effective choices among studied cultivars done to improve and breed these traits. Also the lowest coefficient of variation was for days

Table 2. Descriptive statistics for studied traits.

\begin{tabular}{|c|c|c|c|c|c|c|}
\hline Traits & Variation range & Minimum & Maximum & Mean & $\begin{array}{l}\text { Standard } \\
\text { diviation }\end{array}$ & $\begin{array}{c}\text { Coefficients of } \\
\text { phenotypic variation }\end{array}$ \\
\hline Plant height $(\mathrm{cm})$ & 142.5 & 90.0 & 232.5 & 167.4 & 37.7 & 22.5 \\
\hline Days to maturity (day) & 37.5 & 23.5 & 61.0 & 53.0 & 6.5 & 12.2 \\
\hline Number of nodes (number) & 23.0 & 4.5 & 27.5 & 18.1 & 5.5 & 30.1 \\
\hline Number of Leaf (number) & 142.0 & 9.5 & 151.5 & 64.9 & 30.7 & 47.3 \\
\hline $\begin{array}{l}\text { Number of male flowers } \\
\text { (number) }\end{array}$ & 72.5 & 3.0 & 75.5 & 31.9 & 16.5 & 51.8 \\
\hline Internode length $(\mathrm{cm})$ & 6.2 & 5.9 & 12.0 & 7.8 & 1.3 & 16.2 \\
\hline Fruit length $(\mathrm{cm})$ & 25.5 & 7.5 & 33.0 & 21.6 & 6.2 & 28.9 \\
\hline Fruit width $(\mathrm{cm})$ & 21.5 & 5.5 & 27.0 & 17.5 & 4.9 & 27.8 \\
\hline Fruit length/width ratio & 17.0 & 5.0 & 22.0 & 15.7 & 4.4 & 28.2 \\
\hline 100-seed weight (gr) & 19.8 & 7.5 & 27.3 & 15.4 & 4.0 & 25.8 \\
\hline Plant branches (number) & 14.0 & 1.0 & 15.0 & 7.6 & 3.5 & 46.3 \\
\hline Fruit weight $(\mathrm{kg})$ & 6.3 & 0.6 & 6.9 & 4.3 & 1.4 & 32.5 \\
\hline Flesh weight $(\mathrm{kg})$ & 4.0 & 0.2 & 4.2 & 2.0 & 0.9 & 44.1 \\
\hline Skin thickness (mm) & 1.4 & 0.6 & 2.0 & 1.4 & 0.4 & 27.1 \\
\hline Seed length $(\mathrm{mm})$ & 6.8 & 0.7 & 7.5 & 1.7 & 1.3 & 77.7 \\
\hline Seed width (mm) & 0.7 & 0.4 & 1.1 & 0.8 & 0.1 & 16.9 \\
\hline Seed thickness (mm) & 0.1 & 0.1 & 0.2 & 0.2 & 0.0 & 15.2 \\
\hline Leaf length (cm) & 9.5 & 11.3 & 20.8 & 15.6 & 2.4 & 15.1 \\
\hline $\mathrm{pH}$ & 3.1 & 2.7 & 5.8 & 5.3 & 0.5 & 9.0 \\
\hline
\end{tabular}


to maturity and $\mathrm{pH}$ and improvement of these traits in the study population compared to other traits through selection would be less successful. The standard deviations, minimum and maximum values were comparable among the ecotypes and this indicates the morphological diversity does coincide by different regions. Although, Solmaz \& Sari (2009) showed that there is no genetic variation for traits among the varieties of watermelon.

\section{Cluster analysis based on the all traits}

To obtain an idea about the extent of the similarities and differences among the studied populations based on the studied traits, cluster analysis was performed using different methods such as the average distance between and within groups, the closest and furthest neighbors and Ward minimum variance method and their grouping results were compared. Since the UPGMA method (Euclidean distance criterion) presented the best results in grouping of the studied landraces, therefore, only the results of this method were reported (Fig. 1). Cluster analysis showed that 38 ecotypes watermelon classified into four groups. The first group (1) included ecotypes No: 14, 16, 18 and 37, respectively. The second group (2) included ecotypes No: 8,12 , and 36 , the third group (3) concluded ecotypes No: $4,6,9,17,21,22,23,24,27,29$ and 33 and other ecotypes were placed in the fourth group (4). The maximum distance was observed between Isfahan-Sefid (185.45) ecotypes and Hejrak-Sefid (181.21) ecotypes. The minimum distance was observed among Bushire- Qazvin (10.61) ecotypes and Gerd-Deh-e Ali-Ravar (12.45) ecotypes (data not shown). Solmaz \& Sari (2009) showed that the watermelon accessions were divided into five main clusters whereas in our study were divided into four groups. Overall, this study

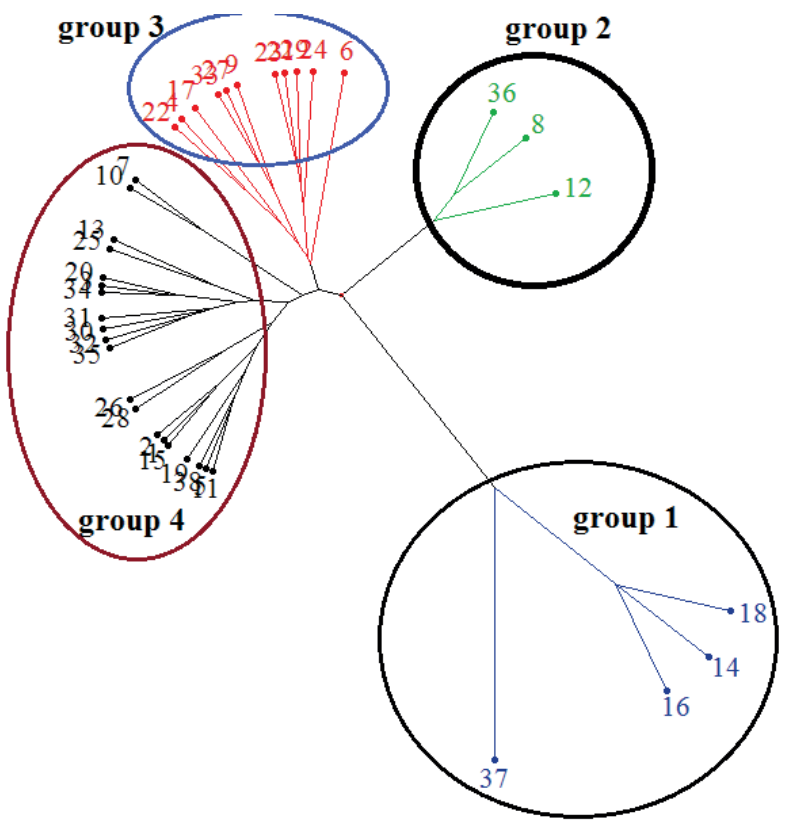

Fig. 1. Grouping the watermelon ecotypes based on agro-morphological traits using UPGMA method. The symbols for the ecotypes are presented in Table 1 . demonstrated medium genetic diversity among cultivated watermelon Which can be due to their narrow genetic background as reported by Bisognin (2002) and Levi et al. (2001). Narrow genetic diversity among inbred cultivars can has occurred in quest for uniformity and selection for earliness, fruit size, color, shape, less bitter flesh, larger and fewer seeds in breeding processes. This selection has resulted in high homozygous and true breeding cultivars, which are more uniform and homogeneous than previous open pollinated (Bisognin 2002).

\section{Molecular characterization of ISSR}

In this study, eleven ISSR primers were used. ISSR markers produced a total of 99 bands, of which 89 bands were polymorphic and the average polymorphic loci per primer were evaluated 8.09 (Tab. 3). Twelve ISSR primers created 89 polymorphic bands among them UBC811 with 15 bands and UBC823 primers with 10 bands had the highest number of polymorphic bands and UBC 824 with 3 bands had the lowest number of polymorphic bands. The mean of polymorphism percentage in the ecotypes was obtained 89.93 for ISSR markers. In this study, we attempted to determine the genetic relationships among 38 ecotypes of watermelon using ISSR marker. These results indicated that ISSR marker is a useful method to detect considerable polymorphisms in watermelon ecotypes from different regions. Gama et al. (2013) using 13 microsatellites primer studied the genetic diversity of watermelon and observed 33 bands were polymorphic. In other studied, the genetic diversity of Turkish watermelon was investigated with using fourteen SSR primers and 31 SRAP primer combinations. The polymorphisms of both SSR markers (100\%) and SRAP markers $(97.3 \%)$ were high. The results of cluster and principle coordinate analyses showed highly similar among watermelon genotypes collected from the different regions of Turkey (Solmaz et al. 2016).

Shannon's information index and Nei genetic diversity ranged from 0.39 to 0.57 (average: 0.41 ) and 0.24 to 0.39 (average: 0.29 ), respectively (Tab. 3). These results indicating a medium level of differentiation among studied watermelon ecotypes. Polymorphic information content (PIC) is the equivalent of genetic diversity and shows the resolution of a marker by the number of polymorphic alleles and the frequency of these alleles in the studied population. The PIC calculated separately for each primer and the results are presented in Table 3. The PIC ranged from 0.20 to 0.32 with average 0.24 for ISSR markers. Solmaz et al. (2016) observed that PIC values ranged between 0.40 (Cgb4765) and 0.83 (CMCT44) for SSR marker and 0.48 (me3em5) to 0.84 (me3em2 and me9em 11) for SRAP marker. Also, Gama et al. (2013) indicated maximum and minimum PIC values loci for MCPI_12 (0.683) and MCPI_14 (0.186), respectively with average 0.391 . Vaiman et al. (1994) and Xie et al. (2010) reported that PIC values change in High: $\mathrm{PIC}>0.5$, medium: $0.5>\mathrm{PIC}>0.25$ and low: $\mathrm{PIC}<0.25$. In this study, the medium PIC value $(0.32)$ was obtained for primer UBC811, suggesting that it, as the 
Table 3. ISSR markers characteristics used in this study.

\begin{tabular}{|c|c|c|c|c|c|c|c|}
\hline ISSR Primers & $\begin{array}{c}\text { No. of } \\
\text { Polymorphic bands }\end{array}$ & $\begin{array}{l}\text { Total } \\
\text { bands }\end{array}$ & $\%$ Polymorphism & $\mathrm{PIC}$ & Shannon & Nei & $\begin{array}{c}\text { Number of effective } \\
\text { alleles }\end{array}$ \\
\hline UBC811 & 15 & 15 & 100 & 0.32 & 0.51 & 0.34 & 1.56 \\
\hline UBC812 & 8 & 9 & 88.8 & 0.31 & 0.57 & 0.39 & 1.69 \\
\hline UBC813 & 9 & 10 & 90 & 0.22 & 0.43 & 0.28 & 1.47 \\
\hline UBC815 & 7 & 8 & 87.5 & 0.25 & 0.47 & 0.30 & 1.47 \\
\hline UBC816 & 8 & 9 & 88.8 & 0.21 & 0.40 & 0.25 & 1.40 \\
\hline UBC817 & 6 & 7 & 85.7 & 0.21 & 0.40 & 0.26 & 1.43 \\
\hline UBC823 & 10 & 12 & 83.3 & 0.21 & .041 & 0.26 & 1.43 \\
\hline UBC824 & 3 & 3 & 100 & 0.22 & 0.41 & 0.25 & 1.37 \\
\hline UBC825 & 8 & 9 & 88.8 & 0.21 & 0.41 & 0.26 & 1.43 \\
\hline UBC826 & 8 & 9 & 88.8 & 0.20 & 0.39 & 0.24 & 1.37 \\
\hline UBC876 & 7 & 8 & 87.5 & 0.28 & 0.52 & 0.34 & 1.56 \\
\hline Mean & 8.09 & 9 & 89.93 & 0.24 & 0.41 & 0.29 & 1.47 \\
\hline
\end{tabular}

most informative marker, could be highly useful for the study of genetic diversity between watermelon ecotypes. The number of effective alleles was different among the studied markers. The average number of effective alleles was calculated 1.47 in the population and ranged between 1.37-1.69. UBC812, and UBC811 and UBC876 had the highest number of effective alleles among the all ecotypes. Since the number of effective alleles is one of the important criteria in the selection of appropriate and useful primers, these primers could be used to investigate the genetic diversity of watermelon ecotypes for the future studies.

\section{Cluster analysis}

In order to group the studied populations and assess their relationships by ISSR marker, cluster analysis was performed using UPGMA method with Jaccard similarity distance. The UPGMA clustering exhibited four distinct groups (Fig. 2). In this grouping, the accessions did not group in geographical origins or clustering based traits and showed evidence of mixed ancestry. The first group (A) contains 5 ecotypes. The second group (B) includes 8 ecotypes. The third group (C) concludes 15 ecotypes and fourth group (D) had 10 ecotypes.

In this study, genetic distance (GD) values ranged between 0.018 (Sabzevar ecotype vs. B ecotype) to 0.426 (Baft ecotype vs. Binam ecotypes) and the average of GD was estimated about 0.197 (data not shown). According to high genetic similarity values and low private band among studied different watermelon ecotypes from different region this hypothesis was confirmed that watermelon ecotypes may have been originated from the common ancestry. High genetic similarity among watermelon ecotypes can be due to artificial selection by humans over a long duration breeding programs, improved by sequential selection of the best traits (Kwon et al. 2010) and due to the asexual propagation of the species (Hwang et al. 2011). Thus, the present results indicated the robustness of the ISSR technique in providing a higher degree of resolution for discriminating closely related genotypes within the species of watermelon. Genetic variation does not know based on morphological variation due to interaction between environment and genotype, and did not large inform about the genetic control of complex traits. Beyene et al. (2005) also showed that the traits do not have much use to identify closely related accessions and genetic analysis of relationships. Despite these limitations, morphological and agronomic traits due to being quick and simple to early evaluate are useful for genetic diversity and this method are known as a primary method of assessing genetic diversity of populations. Because morphological variation alone does not reflect the total variation which is necessary for breeding new genotypes, newer techniques such as isozyme, protein, molecular markers and quantitative characters must be used in order to provide a complete view about the genetic variation of populations Beyene et al. (2005).

Mantel test was finally done to provide a comparison between extracted similarity matrices from ISSR marker and morpho-agronomic traits. The ISSR similarity matrix and the same extracted matrix from morpho-agronomic traits presented a non-significant correlation $(\mathrm{r}=0.03)$.

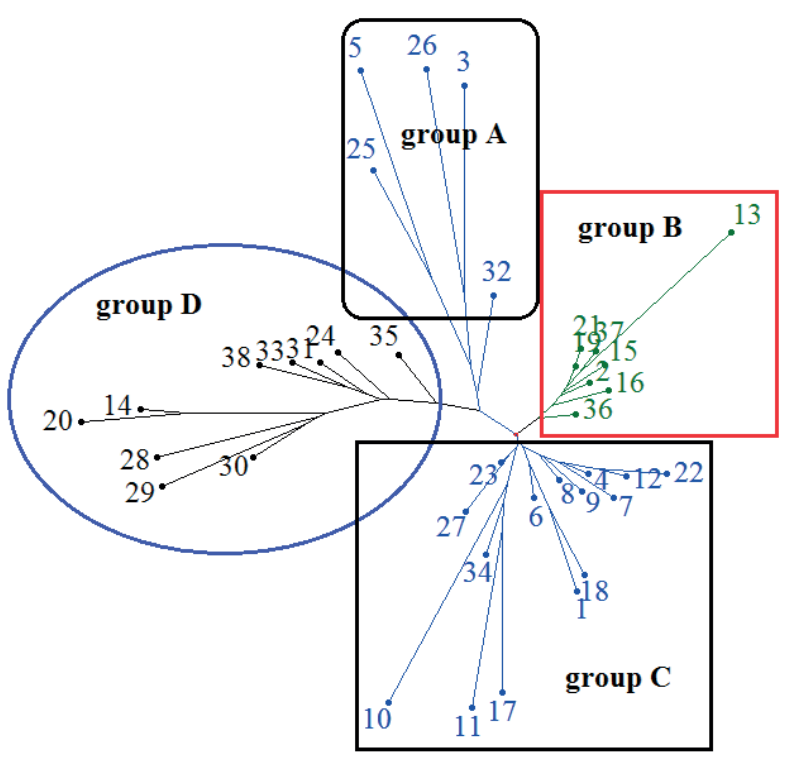

Fig. 2. Grouping the watermelon ecotypes based on ISSR marker. The symbols for the ecotypes are presented in Table 1. 
Because of phenotypic data are strongly influenced by environmental conditions thus genetic studies based on morpho-agronomic characteristics have been thought to be of low accuracy Vieira et al. 2007). In contrast, in recent years, there has been a significant increase in the application of molecular genetic methods to assess genetic relationships between watermelon and related wild species.

This study supports that quantitative traits are useful tool for preliminary evaluation of genetic diversity in watermelon ecotypes. Selection of parents must be based on the wider inter cluster distance and superior mean performance for fruit yielding and quality in four distinct groups. The ecotype, namely, Yazd was found to be superior for $\mathrm{pH}$, flesh weight and Thickness of pericarp, so it should be utilized in further breeding program for developing superior varieties. Also, the Neyshabor accession showed the maximum seed length, width, diameter and 100 seed weight, so it could be used for production of large size seed cultivars. Also, the genetic parameters such as polymorphic bands (average: 8.09), Shannon's information index (average: 0.41), GD (average: 0.197) and PIC (average: 0.24 ) indicated that ISSR marker is particularly valuable for evaluation genetic diversity among watermelon. The result indicated that the ISSR markers could be a powerful tool to assess the genetic variability of the ecotypes.

\section{ACKNOWLEDGEMENTS}

We gratefully acknowledge the research funding provided for this project (No. 92033924) by Iran National Science Foundation (INSF) and Graduate University of Advanced Technology, Kerman, Iran.

\section{REFERENCES}

Beyene, Y., Botha, A.M. \& Myburg, A.A. 2005. A comparative study of molecular and morphological methods of describing genetic relationships in traditional Ethiopian highland maize. African Journal of Biotechnology 4(7):586-595.

Bisognin, D.A. 2002. Origin and evolution of cultivated cucurbits. Ciência Rural 32(4):715-723.

Capeloto, A., Uneda, S.H. \& Mauro, A.O. 2004. Caracterização molecular entre e dentro de acessos de melancia através de RAPD-PCR. Agronomia - Revista Científica Eletrônica 5(3):1-4.

Dane, F. \& Liu, J. 2007. Diversity and origin of cultivated and citron type watermelon (Citrullus lanatus). Genetic Resources and Crop Evolution 54(6):1255-1265.

Diniz-Filho, J.A.F., Soares, T.N., Lima, J.S., Dobrovolski, R., Landeiro, V.L., Telles, M.P.D.C., Rangel, T.F. \& Bini, L.M. 2013. Mantel test in population genetics. Genetics and Molecular Biology 36(4):475-485.

Faostat. 2014. FAOSTAT. Food and Agriculture Organization of the United Nations Available at: http://www.fao.org/faostat/en/\#data/ QC, Acessed on 05 August, 2014

Gama, R.N.C.S., Santos, C.A.F. \& Dias, R.C.S. 2013. Genetic variability of watermelon accessions based on microsatellite markers. Genetics and Molecular Research 12(1):747-754.

Guerra-Sanz, J. 2002. Citrullus simple sequence repeats markers from sequence databases. Molecular Ecology Notes 2(3):223-225.

Hammer, Ø., Harper, D. \& Ryan, P. 2001. PAST: Paleontological Statistics Software Package for education and data analysis. Palaeontologia Electronica 4(1):1-9.

Hamrick, J.L. \& Godt, M. 1996. Effects of life history traits on genetic diversity in plant species. Philosophical Transactions of the Royal Society B: Biological Sciences 351(1345):1291-1298.

Hwang, J., Jumsoon, K., Byeonggu, S., Kwanghwan, K. \& Younghoon, P. 2011. Genetic diversity in watermelon cultivars and related species based on AFLPs and EST-SSRs. Notulae Botanicae Horti Agrobotanici Cluj-Napoca 39(2):285-292.

Jarret, R., Merrick, L., Holms, T., Evans, J. \& Aradhya, M. 1996. Simple sequence repeats in watermelon (Citrullus lanatus (Thunb.) Matsum. \& Nakai). Genome 40:433-441.

Joobeur, T., Gusmini, G., Zhang, X., Levi, A., Xu, Y., Wehner, T., Oliver, M. \& Dean, R. 2006. Construction of a watermelon BAC library and identification of SSRs anchored to melon or Arabidopsis genomes. Theoretical and Applied Genetics 112(8):1553-1562.

JuFen, L., Ling, X. \& GuoBin, M. 2009. Identification of watermelon hybrid purity by molecular markers. Acta Agriculturae Shanghai 25(1):72-75.

Kwon, Y.S., Oh, Y.H., Yi, S.I., Kim, H.Y., An, J.M., Yang, S.G., Ok, S.H. \& Shin, J.S. 2010. Informative SSR markers for commercial variety discrimination in watermelon (Citrullus lanatus). Genes \& Genomics 32(2):115-122.

Lee, H.J., Cho, H.J., Lee, K.A., Lee, M.S., Shin, Y.S., Harn, C.H., Yang, S.G. \& Nahm, S.H. 2007. Development of sequence-based DNA markers for evaluation of phylogenetic relationships in Korean watermelon varieties. Journal of Crop Science Biotechnology 10:98105.

Lefebvre, V., Goffinet, B., Chauvet, J., Caromel, B., Signoret, P., Brand, R. \& Palloix, A. 2001. Evaluation of genetic distances between pepper inbred lines for cultivar protection purposes: comparison of AFLP, RAPD and phenotypic data. Theoretical and Applied Genetics 102(5):741-750.

Levi, A., Thomas, C.E., Wehner, T.C. \& Zhang, X. 2001. Low genetic diversity indicates the need to broaden the genetic base of cultivated watermelon. HortScience 36(6):1096-1101.

Levi, A., Wechter, P. \& Davis, A. 2009. EST-PCR markers representing watermelon fruit genes are polymorphic among watermelon heirloom cultivars sharing a narrow genetic base. Plant Genetic Resources $7(1): 16-32$.

Liu, K. \& Muse, S.V. 2005. PowerMarker: an integrated analysis environment for genetic marker analysis. Bioinformatics 21(9):21282129.

Mantel, N. 1967. The detection of disease clustering and a generalized regression approach. Cancer Research 27(2 Part 1):209-220.

Mondini, L., Noorani, A. \& Pagnotta, M.A. 2009. Assessing plant genetic diversity by molecular tools. Diversity 1(1):19-35.

Muhammed, A. 2012. Genetic diversity in plants. Springer Science \& Business Media. (see rules)

Mujaju, C., Sehic, J., Werlemark, G., Garkava-Gustavsson, L., Fatih, M. \& Nybom, H. 2010. Genetic diversity in watermelon (Citrullus lanatus) landraces from Zimbabwe revealed by RAPD and SSR markers. Hereditas 147(4):142-153.

Murray, M. \& Thompson, W.F. 1980. Rapid isolation of high molecular weight plant DNA. Nucleic Acids Research 8(19):4321-4326.

Nybom, H. 2004. Comparison of different nuclear DNA markers for estimating intraspecific genetic diversity in plants. Molecular Ecology 13(5):1143-1155.

Perrier, X. \& Jacquemoud-Collet, J. 2006. DARwin software. Available at: http://darwin.cirad.fr/darwin. Acessed on 06 August, 2014

Base SAS ${ }^{\circledR}$ 9.3 Procedures Guide Statistical Procedures. Version 9.3 edn. SAS Institute Inc, Cary, NC. 515 p.

Silva, M.L., Queiróz, M.A., Ferreira, M.A.J.F. \& Buso, G.S. 2006. Morphological and molecular characterization of watermelon. Brazilian Horticulture 24(4):405-409.

Solmaz, I., Kaçar, Y., Sari, N. \& Şimşek, Ö. 2016. Genetic diversity within Turkish watermelon [Citrullus lanatus (Thunb.) Matsumura $\&$ Nakai] accessions revealed by SSR and SRAP markers. Turkish Journal of Agriculture and Forestry 40(3):407-419.

Solmaz, I. \& Sarı, N. 2009. Characterization of watermelon (Citrullus lanatus) accessions collected from Turkey for morphological traits. Genetic Resources and Crop Evolution 56(2):173-188.

Vaiman, D., Mercier, D., Moazami-Goudarzi, K., Eggen, A., Ciampolini, R., Lépingle, A., Velmala, R., Kaukinen, J., Varvio, S.L. \& Martin, 
P. 1994. A set of 99 cattle microsatellites: characterization, synteny mapping, and polymorphism. Mammalian Genome 5(5):288-297.

Vieira, E.A., Carvalho, F.I.F., Bertan, I., Kopp, M.M., Zimmer, P.D., Benin, G., Silva, J.A. Hartwig, I., Malone, G. \& Oliveira, A.C. 2007.

Association between genetic distances in wheat (Triticum aestivum L.) as estimated by AFLP and morphological markers. Genetics and Molecular Biology 30(2):392-399.
Xie, W.G., Zhang, X.Q., Cai, H.W., Liu, W. \& Peng, Y. 2010. Genetic diversity analysis and transferability of cereal EST-SSR markers to orchardgrass (Dactylis glomerata L.). Biochemical Systematics and Ecology 38(4):740-749.

Zhang, D. \& Jiang, X. 2001. Mating system evolution, resource allocation, and genetic diversity in plants. Acta Phytoecological Sinica 25(2):130143. 